\title{
Smart cements: repairs and sensors for concrete assets
}

\author{
Lorena Biondi*a, Marcus Perry ${ }^{\mathrm{a}}$, Christos Vlachakis ${ }^{\mathrm{a}}$, Andrea Hamilton ${ }^{\mathrm{a}}$ \\ aUniversity of Strathclyde, Department of Civil and Environmental Engineering, 75 Montrose Street, \\ G1 1XJ, Glasgow, Scotland, United Kingdom +44(0)141 5484942. \\ *lorena.biondi@strath.ac.uk
}

\begin{abstract}
Smart cements offer a unique opportunity to unify our approach to the remote monitoring and repair of concrete assets. Here, we present our latest progress in manufacturing and testing smart cement sensor-repairs based on fly ash geopolymers - a novel class of cement-like binders that cure to a strong, chemically resistant, electrically conductive shell. Since chloride and moisture are two of the leading causes of degradation of reinforced concrete, we are proposing a technology that is able to monitor chloride ingress into concretes at different levels of moisture. The main task of the work was to manufacture geopolymer binders for concrete specimens, and to cure them at ambient temperatures. We have studied how practical considerations, such as the concrete substrate's maturity, can affect how or whether smart cements can be applied, thus understanding the main limitations of the technology. By using electrical impedance measurements, we aim to demonstrate that geopolymer skin layers can provide high resolution monitoring of chloride contamination at different levels of moisture. Here we present results which show that smart cements are sensitive to changes in humidity of the surrounding environment. Our goal is to develop a robust and field-worthy technology which unifies civil monitoring and maintenance. This goal is of key national importance to the US and many countries within Europe, who now face an ageing population of reinforced concrete bridges, tunnels and support structures.
\end{abstract}

Keywords: Smart cements, structural monitoring, concrete repair, geopolymer binders, Electrochemical Impedance Spectroscopy

\section{INTRODUCTION}

Monitoring and maintenance are major requirements to ensure the structural health of civil infrastructure. Currently, there is a growing interest in combined monitoring and maintenance technologies, in particular through the application of 'smart cements'. These cements can act as repairs for concrete structures and simultaneously undergo measureable changes in electronic impedance in response to environmental conditions [1]. The smart cement sensor patches utilized in this work are fly ash geopolymer binders, a novel class of chemically stable, low shrinkage, piezoresistive materials, which are highly suited to civil applications [2]. They provide excellent adhesion to concrete structures [3] and they have recently been used to monitor strain and temperature with a high resolution $\left(10 \mu \varepsilon\right.$ and $0.1{ }^{\circ} \mathrm{C}$ respectively) [2] [4].

Chlorides and moisture are two leading causes of reinforced concrete degradation, and so form the measurands of interest in this work [5]. These degradation pathways are particularly important in a nuclear context, where concrete assets are usually coastal and may underpin safety-critical structures and radiation barriers. Here we present the first results of a research project, which couples smart cementitious repair materials with an electrical system for chloride / moisture sensing. Numerous methods are outlined in the literature for monitoring moisture or humidity levels in concrete [1], and several methods have been used to monitor and detect the chloride content in reinforced concrete. The geopolymer patch sensors in this work are distinct from these methods since they uniquely also protect against subsequent chloride ingress. They thus form a combined monitoring and maintenance technology that is also affordable, distributed, and applicable to surfaces of any size and shape.

In the field of concrete structure rehabilitation, since cracking and spalling are the major causes of deterioration of concrete structures, patching (or coating) is one of the most frequently-used repair methods [6] [7]. Geopolymers have shown promise in this field as they offer high durability, a versatile range of physical properties, and endurance to extreme environmental conditions [3]. Over the years, geopolymers have been exploited as protective coating materials for marine concrete and transportation infrastructures [8] [9]. One of the challenges of applying geopolymers in the field, however, is that they are typically cured at elevated temperatures above $40{ }^{\circ} \mathrm{C}$. Recent work has studied the curing of bulk geopolymer 
specimens at room temperature [10] [11], but there are no specific and detailed studies regarding the curing of geopolymer skin-layers applied to existing concrete structures. The application of geopolymers to a concrete substrate introduces new issues, which we investigate in detail in the present work. In particular, this work presents the first results of curing geopolymer patches on concrete surfaces in-situ at room temperature. In doing so, we hope to push the limitations of this novel sensor-repair technology so that it can be more conveniently applied to real concrete structures in field conditions.

\section{THEORY}

\subsection{Fly ash geopolymers}

Geopolymers are synthetized by adding an alkaline [12] activator solution (in this work, sodium hydroxide $\mathrm{NaOH}$ and sodium silicate $\mathrm{Na}_{2} \mathrm{SiO}_{3}$ ) to raw materials which are rich in aluminum and silicon. Examples include blast furnace slag, metakaolin and fly ash [13] [14]. Geopolymers derived from fly-ash offer key advantages, such as high workability, durability and strength [15] [16]. Moreover, since fly ash is a by-product of coal combustion, it is cheap and available in large volumes around the world [16], retaining good availability even today, as around one billion tons of fly ash are produced annually worldwide in coal-fired steam power plants [17]. For these reasons, fly ash was chosen to synthesize geopolymers in this work.

The exact mechanisms which take place during geopolymerization are still not fully understood [13] [14], but the consensus today is that there are three concurrent stages, illustrated in Figure 1:

1) Dissolution of the fly ash in the alkaline activator: this consists of the severance of covalent bonds $\mathrm{Si}-\mathrm{O}-\mathrm{Si}, \mathrm{Al}-\mathrm{O}-\mathrm{Al}$ and $\mathrm{Al}-\mathrm{O}-\mathrm{Si}$ in the fly ash, and in the formation of intermediate complexes, called oligomers;

2) Coagulation-condensation (gelation): in which oligomers polycondense and the formation of a "geopolymer gel" takes place;

3) Hardening: when after gelation, the system continues to rearrange and reorganize. The connectivity of the gel network increases, and the result is a $3 \mathrm{D}$ aluminosilicate network or "geopolymer".

Fly ash geopolymers can be used as electronic skin sensors because the amorphous $\mathrm{Si}-\mathrm{O}-\mathrm{Al}$ geopolymer network is charge-balanced by $\mathrm{Na}+$ ions [4]. Around half of these ions remain mobile after curing, and this allows them to carry an electrical current. It is believed that $\mathrm{Na}+$ ion mobility within geopolymers is strongly supported by moisture that resides in the pore solution. Geopolymers can thus exhibit an electrolytic conductivity that depends on measurands that impede or encourage $\mathrm{Na}+$ ion mobility, such as strain, temperature, moisture and other contaminant ions [18].

\subsection{Chloride and moisture monitoring}

Only recently, some researchers have looked at geopolymer binders as 'smart cements' for structural health monitoring applications, taking advantage of the 'electrolytic nature' of fly ash geopolymers [3] [5] [17]. Chloride and moisture monitoring have not yet been studied, but these represent important measurands for asset prognosis in reinforced concrete structural health monitoring. The goal is to monitor the electrical impedance of geopolymer skin layers and relate this to the measurands of interest through characterization. The set up used in this work is shown in Figure 2. Current is applied at varying frequencies to two outer electrodes, while the voltage is measured across two inner electrodes.

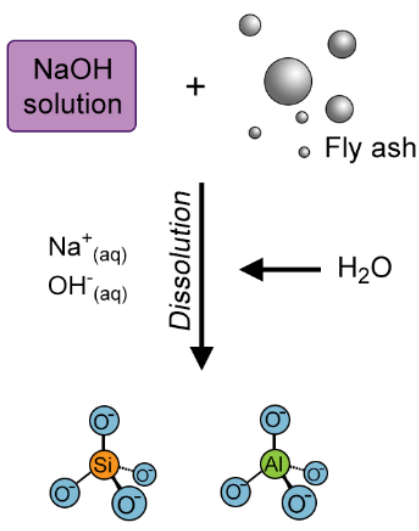

Aluminates and silicates

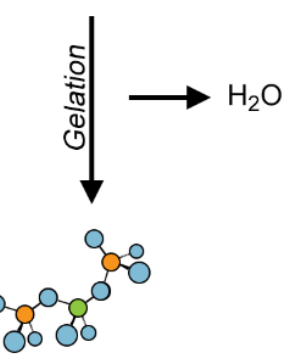

Oligomer formation
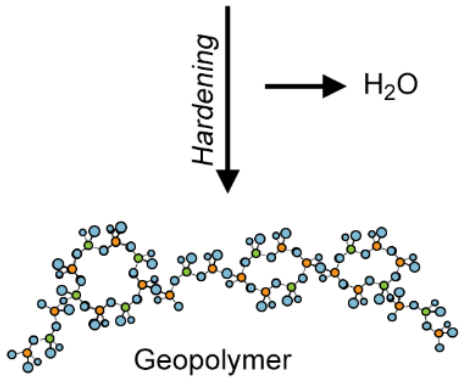

Figure 1. Process of fly ash geopolymerisation 
Electrical Impedance $(\mathrm{Z})$ is the total opposition that a circuit presents to alternating current. The overall impedance response is dependent on the layer's resistance $(\mathrm{R})$, inductance $(\mathrm{L})$, and capacitance $(\mathrm{C})$.

When an alternating current, $I$, is applied across a geopolymer, the measured voltage, $V$, is dependent on the specimen's impedance, $Z$ :

$$
Z=\frac{V_{t}}{I_{t}}=\frac{V_{0} \sin (\omega t)}{I_{0} \sin (\omega t+\varphi)}=Z_{0} \frac{\sin (\omega t)}{\sin (\omega t+\varphi)}
$$

In which $V_{0}$ and $I_{0}$ are the modulus of $\mathrm{V}$ and $\mathrm{I}, \omega$ is the frequency, $\varphi$ is the phase and $\mathrm{t}$ is the time.

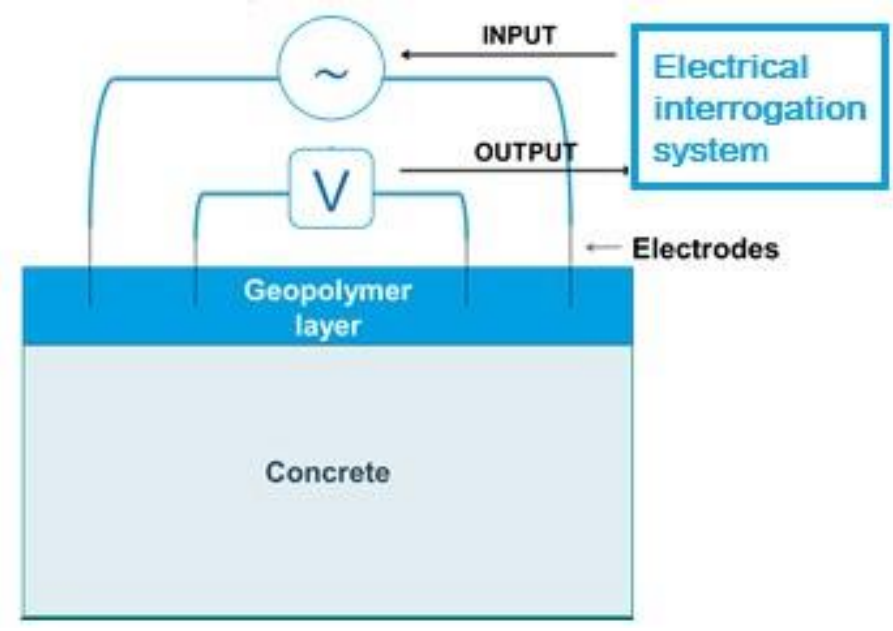

Figure 2. Final system's scheme

Electrochemical Impedance Spectroscopy (EIS) is a technique which provides dense information on sensor substrate's impedance, by measuring the voltage response of a geopolymer layer when currents are applied at a range of frequencies. The conductive medium in the case of this work is the geopolymer layer, which can be considered as a solid electrolyte [19]. Geopolymers primarily have capacitance and resistance. The working principle of the sensor we are developing is based on the fact that moisture and chloride are expected to cause impedance changes at different frequencies. Moreover, cracking will be recorded by the sensor by changes in the resistance of the geopolymer patches.

An EIS spectrum is usually graphed as either a Bode plot (impedance magnitude and phase plotted against frequency) or a Nyquist plot (imaginary impedance plotted against real impedance). The goal is to extract as much information as possible to define the frequencies at which interrogation provides maximum information on moisture and chloride levels in the geopolymer substrate.

\section{MATERIALS AND METHOD}

\subsection{Geopolymer synthesis}

The geopolymer binder in this work was fabricated by combining $68 \mathrm{wt} \%$ low calcium fly ash with 34 wt $\%$ of alkaline solution, made by $10 \mathrm{wt} \%$ of $10 \mathrm{M}$ sodium hydroxide solution $(\mathrm{NaOH})$ and $24 \mathrm{wt} \%$ sodium silicate solution $(\mathrm{Na} 2 \mathrm{SiO} 3$, with $8.5 \mathrm{wt} \% \mathrm{Na} 2 \mathrm{O}$ and $27.8 \mathrm{wt} \% \mathrm{SiO} 2$, in distilled water).

The mixing procedure for the geopolymer consists on adding batches of fly ash powder into a bowl with the alkaline solution, at room temperature $\left(\sim 20^{\circ} \mathrm{C}\right)$, until all the fly ash has dissolved. During this procedure, the resulting binder is mixed continuously for between 10 minutes and 4 hours. The geopolymers were then allowed to rest at room temperature for between 0 hours (no resting time) and 4 hours.

Some steps of mixing and applying the geopolymer binder onto concrete are shown in Figure 3: 

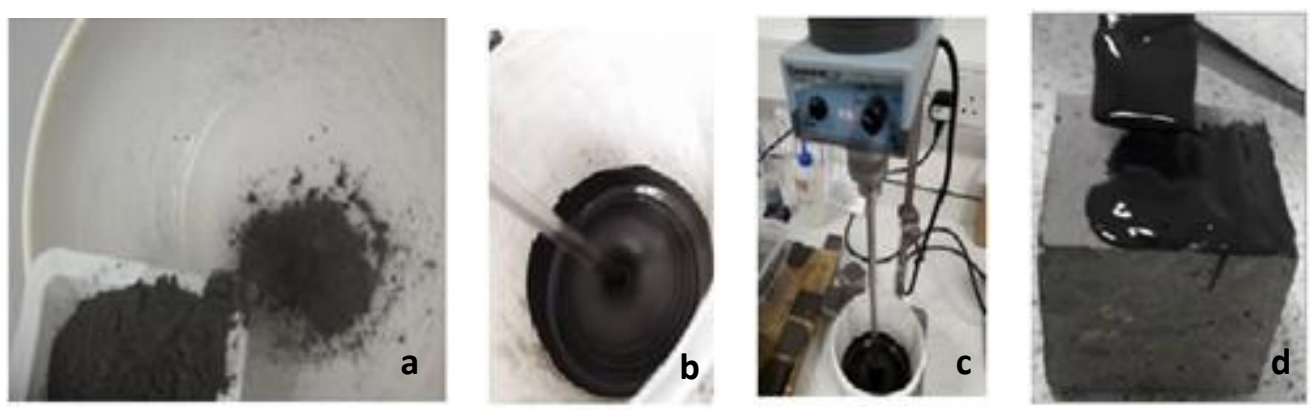

Figure 3. a) The procedure of adding fly ash powder to the alkaline solution; b) and c) automatic mixing of geopolymer binder with a speed of 500 min-1; d) application procedure of geopolymer binder onto concrete surface.

\subsection{Samples manufacture and curing conditions}

Samples of geopolymer were applied to concrete substrates and allowed to cure at room temperature. Electrodes were inserted into some specimens. Concrete slabs of different ages were used to represent the varying concretes found in field conditions:
a) young concrete: less than 3 months old;
b) intermediate concrete: over 6 months old;
c) old concrete: over 3 years old.

All samples were cured at $20^{\circ} \mathrm{C}$, either on a laboratory bench at $50 \%$ Relative Humidity (RH), or in an environmental chamber with a high RH level (80\% to $98 \%$ ). These configurations constitute two environmental conditions which can be found in the targeted field application.

\subsection{Electrochemical impedance testing methods}

Cured geopolymer specimens were attached to an electrical impedance analyzer as shown in Figure 4. We used the Gamry Instruments interface $1000 \mathrm{E}$ with a four configuration electrodes cell (shown in Figure 4) and a Faraday Cage to avoid electrical noise. We chose the range of frequencies from $1 \mathrm{mHz}$ to $1 \mathrm{MHz}$, by using the potentiostatic method. The Potentiostatic EIS technique is used to characterize an electrochemical interface which is held at a fixed potential. A small-signal AC potential excitation $(10 \mathrm{mV})$ is applied to an electrochemical cell. The phase-sensitive AC response of the interface is measured as the frequency of the excitation signal is varied.

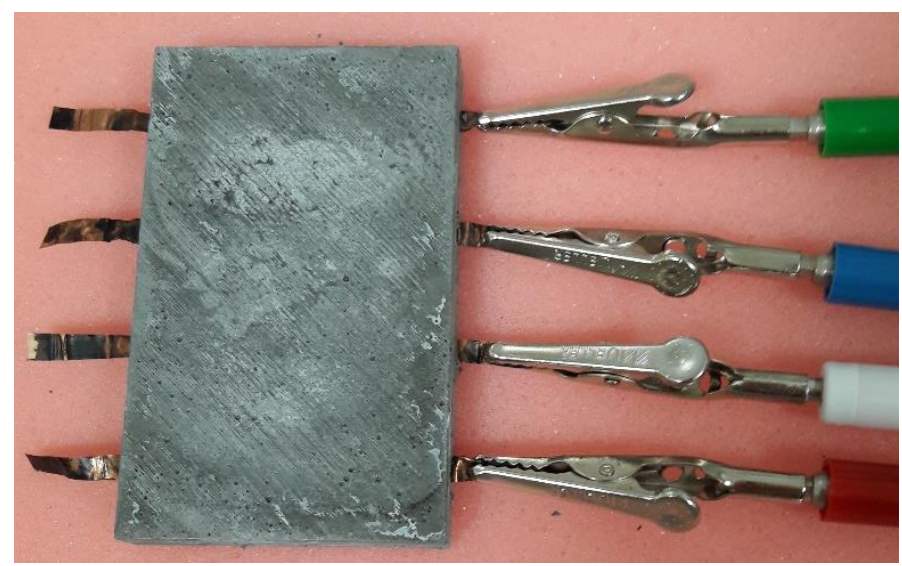

Figure 4. A four-electrode EIS cell with a geopolymer samples and copper electrodes 


\section{RESULTS AND DISCUSSION}

\subsection{Effect of concrete substrate age}

Figure 5 illustrates the difference between geopolymer layers applied to different ages of concrete substrate. The first three images show samples of geopolymer mixed for just a few minutes and then applied to the 3 years old, 6 months old and 3 month old concretes respectively, while the last picture shows a sample of geopolymer mixed for one hour and then applied to a 3 months old concrete specimen. We can see a dependence of the status of the geopolymer patches on the age of the concrete just after few minutes mixing: geopolymers put onto older concrete substrates are less likely to crack. Geopolymers mixed for longer before application are also less likely to show cracks.

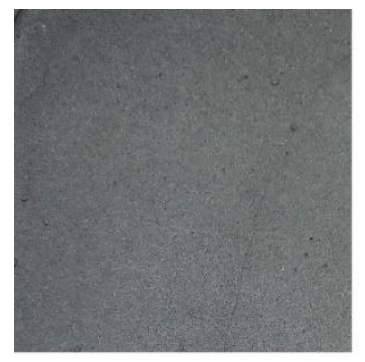

3 years old concrete Few minutes mixing

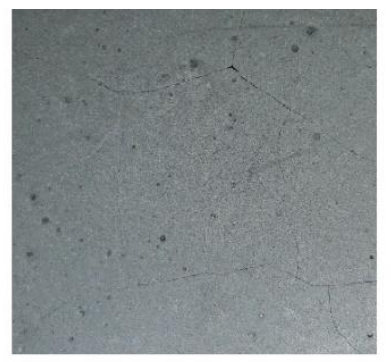

6 months old concrete Few minutes mixing

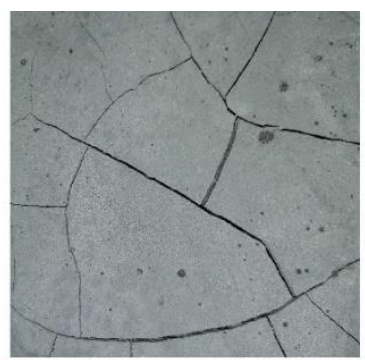

3 months old concrete Few minutes mixing

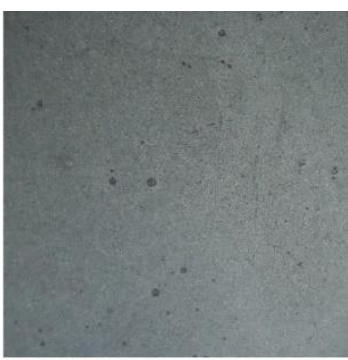

3 months old concrete One hour mixing

Figure 5. From the left to the right, geopolymer patches applied to 3 years old concrete after a few minutes of mixing, geopolymer patches applied to 6 months old concrete after a few minutes of mixing, geopolymer patches applied to 3 months old concrete after a few minutes of mixing, geopolymer patches applied to 3 months old concrete after one hour of mixing.

Cracks are not observed in geopolymer binders cured in plastic moulds, and this suggests that a direct interaction between the geopolymer binder and the concrete surface is to blame. The issue in this case could be drying shrinkage due to a loss of water [20]. Shrinkage is a troublesome issue for geopolymers, especially for geopolymers which take longer to cure as they are not heated above room temperature, as is the case of interest for this project. Shrinkage could be considerable and often leads to cracking: since shrinkage causes volume change, and any volume change that occurs after the binder has partially stiffened will cause stresses to develop. Once the stress developed exceeds the strength of the material, cracks will form leading to a reduction in the load carrying capacity [21]. This loss of moisture causes the tension in the capillary pores to increase and this causes the volume change in the specimen. A key parameter in influencing shrinkage of geopolymer specimens is the moisture content/control. It has been demonstrated [21] that the longer the sample stays in sealed condition, the less shrinkage it exhibits. For this reason, geopolymer sensor-patches are less likely to crack if they are applied to concrete when the major extent of the geopolymerization reactions have already occurred.

Cracking is less likely for geopolymer layers applied to old concretes, because old concretes show lower porosity compared with young concretes [22]. Less is the porosity of the concrete specimen to which the geopolymer is applied, less is the drying shrinkage of the geopolymer layer itself, and consequently less is the cracking.

\subsection{Samples showing efflorescence crystals}

Some samples of fly ash geopolymers applied to concrete, cured at $20^{\circ} \mathrm{C}$ and with an intermediate RH level, after a time ranging from one week to more than a month, start to show white spots on their surface. These can be interpreted as the beginning of efflorescence, as we can see from the image on the left of figure 6 . Figure 6 right shows a one month old sample of geopolymer applied to old concrete, cured in the environmental chamber at $20^{\circ} \mathrm{C}$ and with a $\mathrm{RH}$ level of $98 \%$. It shows a large extent of efflorescence. 

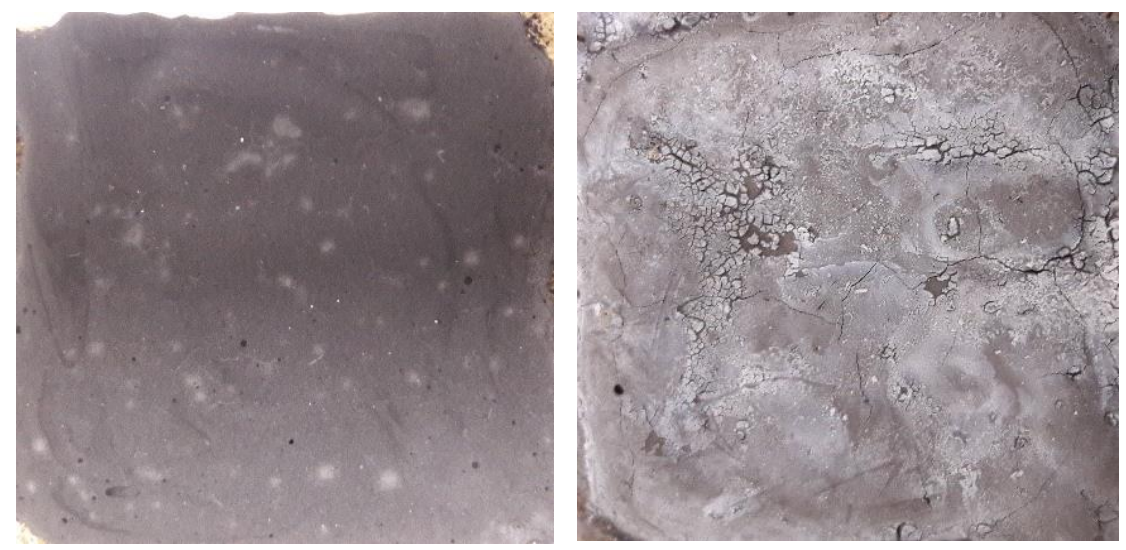

Figure 6. The image on the left shows an over 1 week geopolymer sample applied to old concrete showing white spots on its surface, cured at $20^{\circ} \mathrm{c}$ and with an intermediate RH level; the image on the right shows an over 1 month old geopolymer sample, cured for 3 days in the environmental chamber at $20^{\circ} \mathrm{c}$ and with a RH level of $98 \%$, applied to old concrete showing a large extent of efflorescence.

Efflorescence is the phenomenon consisting of the formation of white salt deposits on or near the surface of concrete and cementitious binders. It has been found that efflorescence is due to many factors, in addition to the wet conditions: reactivity of raw materials [23], alkali metal type [24] [25], and reaction conditions [25]. Room temperature curing doesn't promote a high dissolution rate of the fly ash by the alkaline solution, and therefore excess alkaline solution is crystallizing on the surface [26]. Alkali content is certainly the most important compositional parameter influencing the efflorescence of geopolymers, since free alkali cause efflorescence under wet/partially dry conditions. This could be an issue for this project, since the presence of high concentration of alkali metal cations is an important requirement to use the geopolymer binder as sensor and, at the same time, it is likely that in the field application the relative humidity will be above $70 \%$. It is currently unclear whether efflorescence will affect the geopolymer as a sensor. This will be investigated in future work.

\subsection{EIS results}

The first experiments on geopolymer samples with the EIS technique gave optimistic results. Figure 7, Figure 8 and Figure 9 show, respectively, two Bode plots and the Nyquist plot for a cube of geopolymer $\left(30 \times 30 \times 30 \mathrm{~mm}^{3}\right)$ with stainless steel electrodes at about $6 \mathrm{~mm}$ of distance each other, cured at $20^{\circ} \mathrm{C}$ and $80 \% \mathrm{RH}$ level.

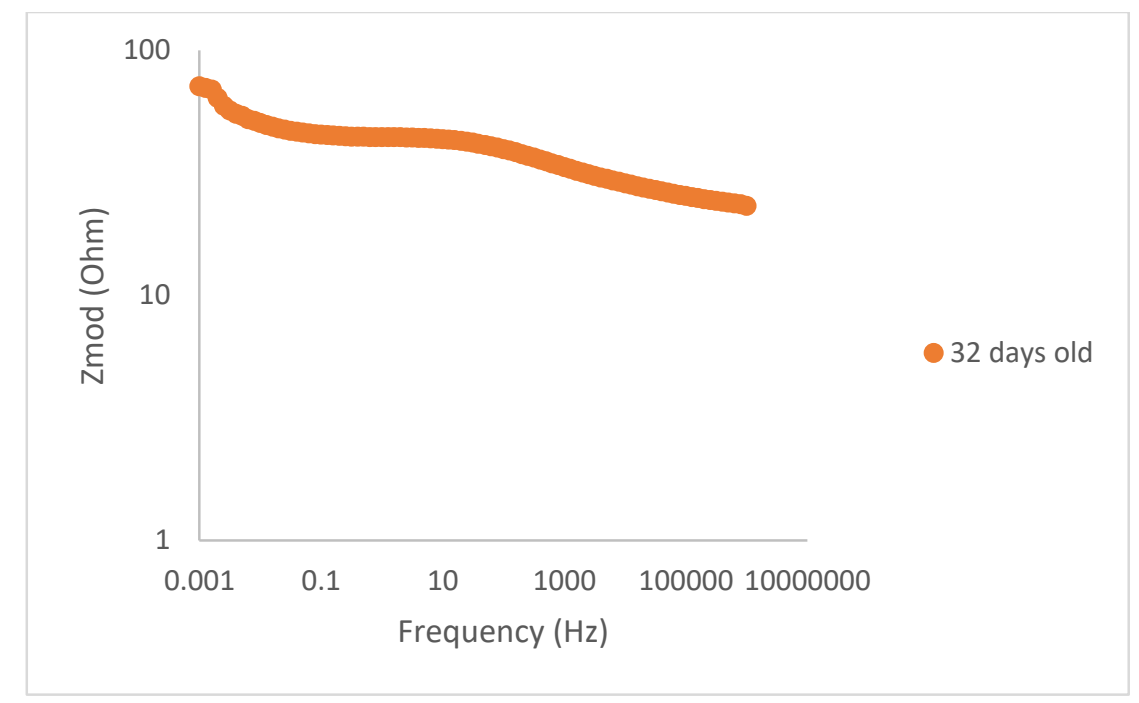

Figure 7. Bode plot (Zmodule) of a geopolymer cube with stainless steal electrodes. 


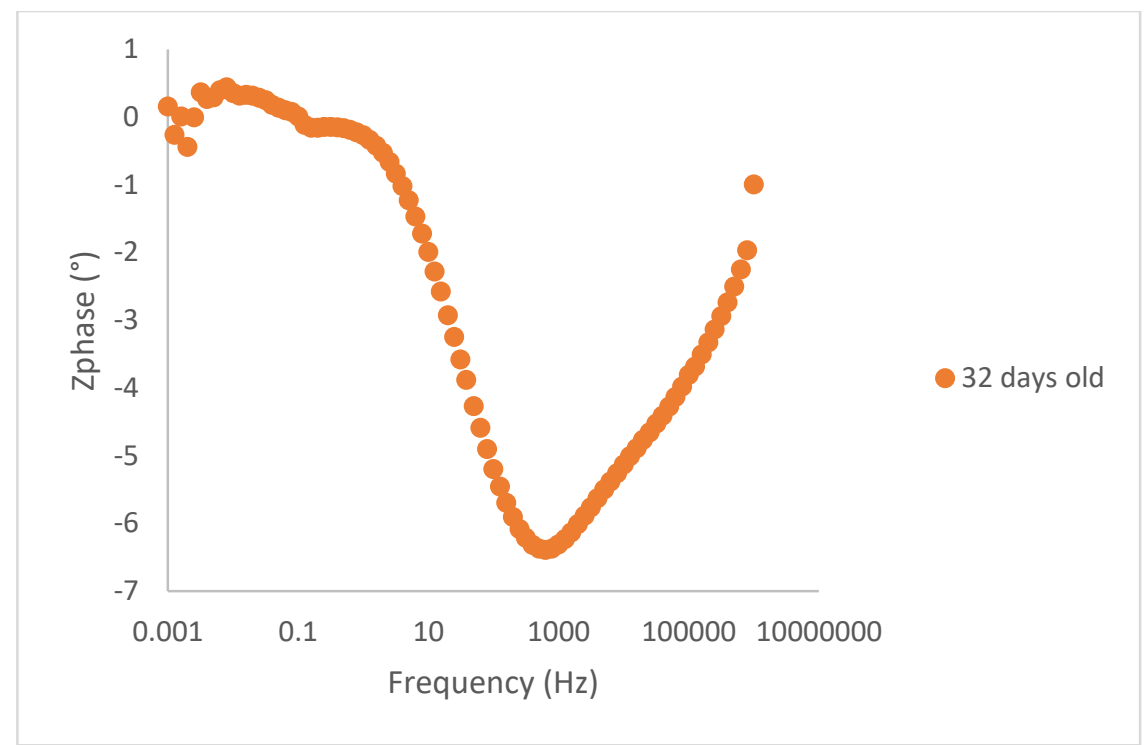

Figure 8. Bode plot (Zphase) of a geopolymer cube with stainless steal electrodes.

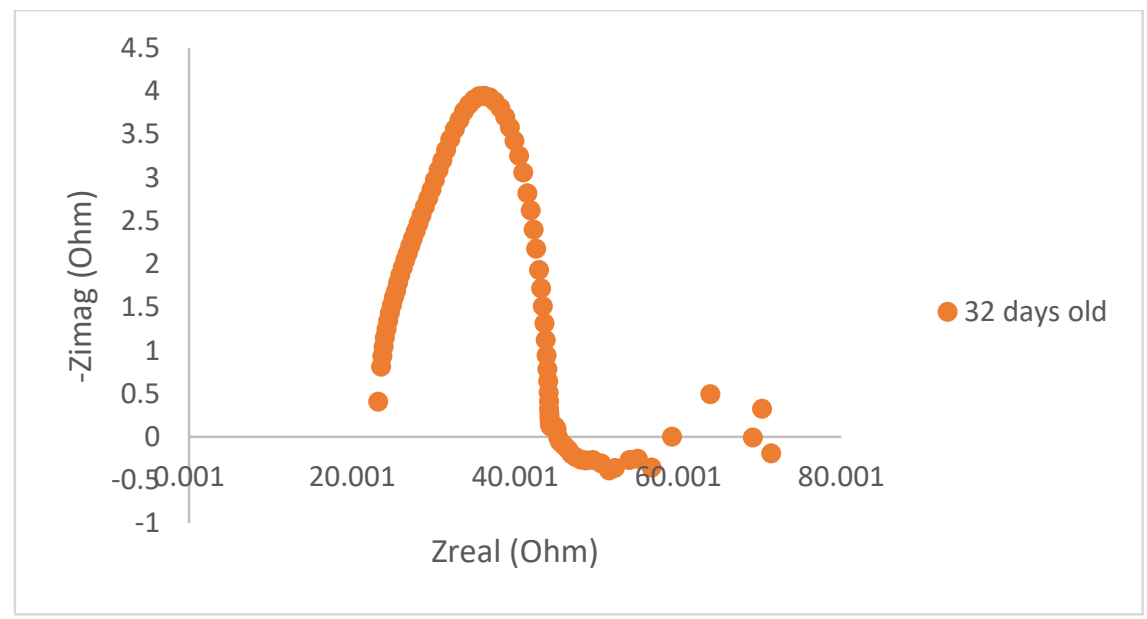

Figure 9. Nyquist plot (Zimag in dependance of Zreal) of a geopolymer cube with stainless steal electrodes.

For the EIS analysis it is important to analyze the electrical components which can be recognized inside the cell in the specific case of application [19]:

1. The electrolyte solution resistance is often a significant factor in the impedance of an electrochemical cell, and it depends on the ionic concentration, type of ions, temperature, and the geometry of the area in which current is carried.

2. A similar resistance to the electrolyte resistance is formed by a single kinetically-controlled electrochemical reaction, which represents the charge transfer resistance. In this case we do not have a mixed potential, but rather a single reaction at equilibrium. When a metal substrate is in contact with an electrolyte, the metal molecules can electrolytically dissolve into the electrolyte, electrons enter the metal and metal ions diffuse into the electrolyte, thus charge is transferred. This charge-transfer reaction has a certain speed, which depends on the kind of reaction, the temperature, the concentration of the reaction products, and the potential. 
3. A double layer capacitance exists at the interface between an electrode and its surrounding electrolyte, where there is an electrical double layer, but capacitors in EIS experiments often do not behave ideally. They act like a constant phase element (CPE). This double layer is formed as ions from the solution "stick to" the surface of the electrode. Charges in the electrode are separated from the charges of these ions. The separation is very small, on the order of tenths of a $\mathrm{nm}$. Charges separated by an insulator form a capacitor. The value of the double-layer capacitance depends on many variables including electrode potential, temperature, ionic concentrations, types of ions, oxide layers, electrode roughness, impurity adsorption, etc. Capacitors in EIS experiments often do not behave ideally. Instead they act like a constant phase element (CPE).

4. Diffusion can create an impedance known as the Warburg impedance, which depends on the frequency of the potential perturbation. At high frequencies the Warburg impedance is small because diffusing reactants don't have to move very far. At low frequencies the reactants have to diffuse farther, thereby increasing the Warburg impedance. On a Nyquist plot, the infinite Warburg impedance appears as a diagonal line with a slope of 0.5. On a Bode plot, the Warburg impedance exhibits a phase-shift of $45^{\circ}$.

Common models made by different combinations of these elements are used as equivalent circuits to interpret simple EIS data. In this case, the plots can be interpreted, at high frequencies, with a Constant Phase Element (CPE) circuit model, shown in Figure 10.

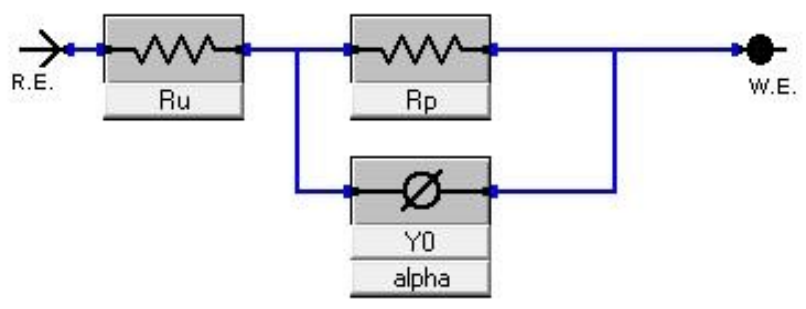

Figure 10. Constant Phase Elements (CPE) circuit model

The result at lot frequencies is still not clear, and it will be investigated in detail, as well as the result at high frequencies in future work.

Another remarkable result is the plots obtained by varying the moisture content of the sample. We casted two samples of geopolymer and cured them for 36 days at the same conditions of temperature $\left(20^{\circ} \mathrm{C}\right)$ and $\mathrm{RH}(80 \%)$. They were tested on the first day, and then kept in the laboratory at an intermediate level of relative humidity for one day, and re-tested. As we can see from the Figure 11 below, the impedance measured the first day is much lower compared with the impedance values measured after one day of drying. 


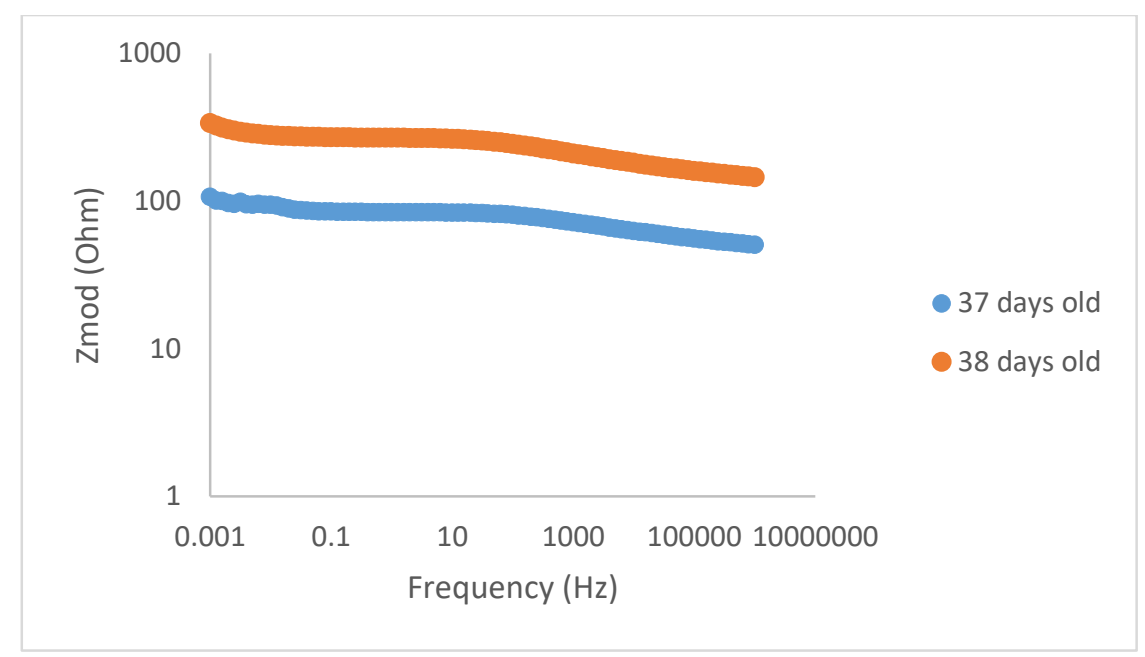

Figure 11. Bode plot $\left(\mathrm{Z}_{\text {module }}\right)$ of a geopolymer sample with copper electrodes measured after 37 and 38 days from casting.

Further investigation are necessary, but these first results show the sensitivity of the system to changes in the moisture level of specimen and the surrounding environment.

\section{CONCLUSIONS}

The main task of this work is to produce geopolymer "smart cement" sensor-repairs that are closer to being suitable for use in field conditions. This work has shown the first results obtained with the sensing system applied to geopolymer samples and in monitoring changes of moisture in the environment. The results coming from the work have been helpful to understand the most suitable geopolymer binder to be applied as patches onto concrete surfaces, even if it is in direct contact with concrete, as well as the mixing and curing conditions of the final samples. The main issues which have been found during the laboratory work are: cracking of geopolymer patches applied to concretes, and the appearance of efflorescence.

The first results of the Electrochemical Impedance Spectroscopy (EIS) technique application to geopolymer samples show that the plots obtained can be related with an equivalent circuit model for the system formed by geopolymers and electrodes. Moreover, the system show sensibility for changes of moisture, since the impedance values change a lot with moisture changes. Further investigations are necessary to identify the values of the elements of the system and to find the best model for the system, to set it as point of start for the chloride monitoring measurements.

Repair to structures and infrastructure maintenance in is a costly problem, and it implies also social costs. For this reason, inspection, monitoring and maintenance are major requirements for the structural health in civil engineering, leading to a better risk control maintenance strategy. Chloride and moisture are two leading causes of deterioration of reinforced concrete structures. A combined technology which allows the continuous measurement of both these parameters is of remarkable importance for the structural health monitoring since it gives the possibility to predict the maintenance actions for the reinforced concrete structures. Moreover, the technology plays the role of repair of concretes, and it allows also an early detection of cracking, since it has been demonstrated that it is sensitive also to strain changes, and the cracking of the geopolymer binders results in changing of its electrical properties, thus allowing to detect any change in the integrity of the binders and consequently any changes in the integrity of the concrete structure itself. 


\section{REFERENCES}

[1] Buenfield, R. D. and Davies, N. R., "Intelligent monitoring of the deterioration of concrete structures," Imperial College London: dti/ciria report..

[2] Torres-Luque, M., Bastidas-Arteaga, E., Schoefs, E., Sanchez-Silva, M. and Osma, J. F., "Non-destructive methods for measuring chloride ingress into concrete: state-of-the-art and future challenges," Hal 01023391 (2014).

[3] Perry, M., Saafi, M., Fusiek, G. and Niewczas, P., "Geopolymeric thermal conductivity sensors for surface-mounting onto concrete structures," Proc. 9th International Concrete Conference, Dundee (2016).

[4] Pacheco-Torgal, F., Castro-Gomez, J. P. and Jalali, S., "Alkali-activated binders: a review," Construction and Building Materials, 22(7), 1305-1322 (2008).

[5] Perry, M., Saafi, M., Fusiek, G. and Niewczas, P., "Hybrid optical-fibre/geopolymer sensor for structural health monitoring of concrete structures," Smart Materials and Structures, 24, 045011 (8pp) (2015).

[6] Wazien, W., Al Bakri, M., Razak, R., Rozainy, M., Faheem, M. and Hussin, K., "Potential of geopolymer mortar as concrete repairing materials," Materials Science Forum, 857, 1662-9752, pp 382-387 (2016).

[7] Shash, A. A., "Repair of concrete beams a case study," Construction and Building Materials, 19(1), 75-9 (2005).

[8] Huseien, G. F., Mirza, J., Ismail, M., Ghoshal, S. K. and Hussein, A. A., "Geopolymer mortars as sustainable repair materials: a comprehensive overview," Renewable and Sustainable Energy Reviews, 80, 54-74. (2017).

[9] Zhang, Z., Yao, X. and Zhu, H., "Potential application of geopolymers as protection coatings for marine concrete: ii. Microstructure and anticorrosion mechanism," Appl. Clay Sci., 49, 7-12 (2010).

[10] Xie, J. and Kayali, O. "Effect of initial water content and curing moisture conditions on the development of fly ashbased geopolymers in heat and ambient temperature," Construction and Building Materials, 67, 20-28 (2014).

[11] Somna, K., Jaturapitakkul, C., Kajitvichyanukul, P. and Chindaprasirt, P., "NaOH-activated ground fly ash geopolymer cured at ambient temperature," Fuel 90, 2118-2124 (2011).

[12] Ichikawa, T. and Kimura, T., "Effect of nuclear radiation on alkali-silica reaction of concrete," J Nucl Sci Technol., 44(10), 1281-1284 (2007).

[13] Provis, J. L. and Van Deventer, J., [Geopolymers, structure, processing, properties and industrial applications], Woodhead publishing in materials (2009).

[14] Davidovits, J., [Geopolymer chemistry and applications], Saint-quentin, France: Institute Géopolymère (2008).

[15] Duxson, P., Fernandez-Jimenez, A., Provis, J. L., Luckey, G. C., Palomo, A. and Van Deventer, J., "Geopolymer technology: the current state of the art," J mater sci, 42, 2917-2933 (2007).

[16] Zhang, Z., Provis, J. L., Reid, A. and Wang, H., "Fly ash-based geopolymers: the relationship between composition, pore structure and efflorescence," Cement and concrete research, 64, 30-41 (2014).

[17] Rashad, A. M., "A comprehensive overview about the influence of different admixtures and additives on the properties of alkali-activated fly ash," Materials and design, 53, 1005-1025 (2014).

[18] Cui, X. M., Zheng, G. J., Han, Y. C., Su, F. and Zhou, J., J. Power Sources, 184, 652-6 (2008).

[19] Lasia, A., [Electrochemical Impedance Spectroscopy and its Applications], New York: Springer-Verlag (2014). 
[20] Lura, P., Jensen, O. M. and Van Breugel, K., "Autogenous shrinkage in high performance cement paste: an evaluation of basic mechanisms," Cement and concrete research, 33(2), 223-232 (2003).

[21] Vijayakumar, R. M., [Evaluating shrinkage of fly ash - slag geopolymers], Master thesis in civil engineering, University of Illinois at Urbana-Champaign (2013).

[22] Palomo, A., Banfill, P. F. G., Fernandez-Jimenez, A. and Swift, D. S., "Properties of alkali-activated fly ashes determined from rheological measurements.," Adv. Cement res., 17, 143-151 (2005).

[23] Škvára, F. and Kopecký, L., "Aluminosilicate polymers - influence of elevated temperatures, efflorescence," Ceramsilikaty, 53, 276-282 (2009).

[24] Szklorzová, H. and Bílek, V., "Influence of alkali ions in the activator on the performance of alkali-activated mortars," The 3rd international symposium on non-traditional cement and concrete, Czech Republic, Brno, (2008).

[25] Škvára, F. and Pavlasová, S., "High temperature properties of fly ash-based geopolymers," The 3rd international symposium on non-traditional cement and concrete, Czech Republic, Brno (2008).

[26] Temuujin, J., Williams, R. P. and Van Riessen, A., "Effect of mechanical activation of fly ash on the properties of geopolymer cured at ambient temperature," Journal of Materials Processing Technology, 209, 5276-5280 (2009). 